\title{
The Effect of External Factors on Purchase Intention amongst Young Generation in Malaysia
}

\author{
Abdolrazagh Madahi ${ }^{1} \&$ Inda Sukati $^{1}$ \\ ${ }^{1}$ Faculty of Management and Human Resource Development, Universiti Technologi Malaysia (UTM), Johor \\ Bahru, Malaysia \\ Correspondence: Abdolrazagh Madahi, Faculty of Management and Human Resource Development, Collage 15 \\ (KTGB), XA2, Room 701, Universiti Technologi Malaysia (UTM), 81310 Johor Bahru, Johor, Malaysia. Tel: \\ 60-16-691-4688. E-mail: khosoof_emaddeh@yahoo.com
}

Received: March 26, 2012

Accepted: April 25, $2012 \quad$ Online Published: July 20, 2012

doi:10.5539/ibr.v5n8p153

URL: http://dx.doi.org/10.5539/ibr.v5n8p153

\begin{abstract}
The purpose of this study is to investigate the effects of demographic (age, gender and race), geographic and group on purchase intention (PI) amongst millennial/young generation in Malaysia. An empirical investigation was carried out to test the hypotheses. The samples include 325 participants. SPSS software has used to measure the effect of external factors on PI. The results demonstrate that demographic, geographic and group significantly affect PI. The findings of this study help marketing, managers and companies to understand young Malaysian consumers' behaviour and PI.
\end{abstract}

Keywords: external factors, purchase intention (PI), young generation, Malaysia

\section{Introduction}

Nowadays, purchase intention is more complicated and more significant for consumers than in the past. Customers are encompassed by reports, advertisements, articles and direct mailings that provide large amount of information. Moreover, different kinds of products, supplies, super markets and shopping malls have complex and difficult decision making.

This study focuses on the young generation in Malaysia because of some reasons. Firstly, immature customer segment is known as special segment for some special products. Secondly, at the period of evolution from youth to early maturity, these customer segments have their unique consumer behaviors and attitudes (Safiek, 2009a). Thirdly, juveniles' effect on their families and shape family's consumer behavior; finally, young consumers can change and influence culture as well as society (Safiek, 2009a).

In addition, according to the previous studies, investigators argued that the external factors (demographic, geographic and group) influence PI. Besides, there are some difficulties in applying these factors and measuring their effects on PI. The effect of demographic on PI is complicated and confusing that needs to be examined. For instance, consumers 18 to 24-year-old are "more likely than other consumers to buy a product on the spur of the moment and change brands if the mood strikes” (Abdol Razak \& Kamarulzaman, 2009). Apart from that, there are still some studies that indicate the males and females behave and make PI in different ways. "Teenage boys were more utilitarian, whereas teenage girls are more social/conspicuous conscious" (Cathy \& Vincent, 2006). Furthermore, different races have different behaviors, which can significantly affect PI; for example, the Malays are more patriotic to the local brands compared to two other Malaysian races. Likewise, group influence significantly affects PI. Group (social networks, television, influential, books) influences on young generation in Malaysia and changes their culture, behavior and purchase intention because they have adapted with other cultures (Fon, Ata \& Philip, 2008).

\section{Literature Review}

Purchase intention means a consumer prefers to buy a product or service because he/she finds that he/she needs a particular product or service, or even attitude towards a product and perception of product. In other words, purchase intention means consumer will buy a product once again after she or he evaluates a product and finds out that the product worth buying. While consumers select one particular product, the final decision on accepting 
a product to buy or rejecting it depends on consumers' intention. Also, a large number of external factors have been recognized, which can affect PI (Keller, 2001).

\subsection{The Effect of Demography on PI}

One of the most important features which influence PI is demographic (age, gender and race). Young consumers in different ages have different behavior. A nineteen years old consumer may behave differently with a twenty five years old consumer. For example, some young consumers are more concerned on the labeled products than other young consumers (Nabil \& Imed, 2010).

The effect of gender depends on some factors. For example, females are more concerned about those kinds of products that are directly related to house because as housewives, the quality of the products is more important for them compared to men. Thereby, label, brands and quality have effects on consumers' PI (Ahasanul, Ali \& Sabbir, 2006; Safiek, 2009b).

The other factors that shape PI among males and females are information and education. For example, a study shows that females are less experienced with online purchasing; therefore, they rely on other recommendations than males during decision making process (Chiao \& Yang, 2010). Atmosphere and environment also influence on consumers' PI among males and females. An investigation shows that music in restaurants has more effect on females than males. (Stephanie Wilson, 2003). In addition, studies showed that men are more risk taking than women and they are more reliance on themselves to make purchase decision than women (Syed, 2003).

Different ethnic groups act differently to make purchase decision. For example, studies in the United States have shown that African-Americans in some cases have different purchase intentions than the whites (Americans). Some factors can have effects on different races such as media, advertisements, and televisions. The other example shows that $16 \%$ of married white women are more likely to do home purchase than married black women in the United States; but some other factors (socio-economic, environment, culture, income) could be combined with race to achieve better outcomes (Chiao \& Yang, 2010).

\subsection{The Effect of Geography on PI}

The other external factor that influences consumers' PI is geography. Locations that products are being produced and manufactured are very important for consumers and can shape their PI. A place to shop for organic products is crucially integral for consumers. For instance, a research demonstrates that majority of consumers prefer to buy their organic food and products from hypermarkets and shopping malls and only a few of them enjoy of buying products in farms (Siti \& Nurita, 2010).

\subsection{The Effect of Group on PI}

Group also affects consumers and their PI. Previous experiences of celebrities have utilized different assumptions and basic theoretical grounds of psychology to describe how a sponsorship as an influential effect consumers' PI and their behavior (Speed \& Thompson, 2000). Sport celebrities as a group of influential figures have significant influences on young consumers especially when they want to make decision to choose a brand and PI. Star members in each team have significant effects on consumer behavior. Thus, they would make brand for the team's sponsor because team members are able to attract enormous amount of consumers for a brand (Rashidah \& Fairuzana, 2006).

\section{Research Methodology}

\subsection{Measures}

Data has been mainly collected based on primary research and secondary research was used as well. Previous literatures were studied to recognize the factors influencing consumer PI. Learning and understanding key points from previous literatures were combined with this current research study to obtain better results.

Sampling strategy is based on probability based. The population is in age group of 17-32 years old as millennial/young generation. Questionnaire has distributed to some Malaysian universities. According to the aim of this research, the race of population has to be Malaysians only and questions were written in English language. The sample was selected from universities (senior and junior students). SPSS software was used to measure/analyze the data.

\subsection{Hypothesis}

Demographic factors positively effects on purchase intention, for example, there is a difference between young consumers and adult generation in the case of purchase intention. In some cases, male and female consumers act differently to make purchase decision and also different races have different influences on purchase intention 
(Heidi, Gerard \& Alex, 2008). Thereby, age, gender and race are strongly affecting PI, which has been proven by previous studies.

\section{H1: (a): Age influence PI \\ (b): Gender influence PI \\ (c): Race influence PI}

Malaysia is divided into two different parts: west and east. Siti (2010) noted that different areas and locations have different effects on consumers' behavior and purchase intention. Consumers in cities and villages (rural and urban) have different behavior and purchase intention (Wong \& Yahyah, 2008). Therefore, rural and urban influence PI differently.

H2: Geographic influence on PI.

Friend, relative, colleague/classmates and Media impact on purchase intention.

\section{H3: Group affects PI.}

\subsection{Data Collection}

The questionnaire in this study has been distributed to 350 respondents. 325 respondents have returned the completed questionnaire, which made up $93 \%$ of overall responses. We have given the questionnaire to students usually in their classes and we had left them and given them enough time to answer the questions. After 30 to 45 minutes we went back to classes and ask students to return questionnaires. The SPSS software has been used to analyze the effects of external factors (demographic, geographic and group influence) on PI. Consumers between 17-32 years old were selected as young generation. The research was carried out at different regions in Malaysia such as International Islamic University Malaysia (IIUM), Universiti Kebangsaan Malaysia (UKM), Universiti Putra Malaysia (UPM), Multimedia University (MMU) and Nation Library. The questions mainly examined the effects of friends, relatives, classmates/colleagues and media on consumers' PI. All scales measured on 7-point Likert-type scales ranging from "strongly disagree" to "strongly agree".

The demographic factor is divided into three separate categories. These three groups involved age, gender and race, which will be explained in the following subsections. As demonstrated in Table 1, most respondents involved are in the age group of 22-26 years old. Analysis shows that $30.2 \%$ of the respondents belong to $17-21$ age group, $40.9 \%$ belong to $22-26$ age group and only $28.9 \%$ are in the age range of $27-32$ years old. The majority of the respondents are females; 221 respondents are female (68\%) and 104 are males, which contributes to $32 \%$ of the total respondents participated in this study. The majority of the people in Malaysia are Malays, so this variable is more than other races. The second largest race in Malaysia is Chinese followed by Indians. Thereby, the questionnaires have been distributed based on the size of race group. $47.7 \%$ of the respondents are Malay, $33.2 \%$ Chinese and $19.1 \%$ Indian.

Geographic group involves urban and rural area. Demographic group demonstrates the influence of urban and rural consumers on PI. 64.3\% of the respondents are staying in urban areas and data have been collected from Kuala Lumpur and Cyberjaya cities. On the other hand, $35.7 \%$ of the respondents in this study come from rural areas. This is due to the fact that the questionnaires have been collected from the universities in Malaysia and for sure, some rural students further their studies at these two cities.

Table 1. Sample of Demographic and Geographic profile

\begin{tabular}{llll}
\hline Demographic and Geographic Factors & & Frequency & Percentage \\
\hline Age & $17-21$ & 98 & 30.2 \\
& $22-26$ & 133 & 40.9 \\
& $27-32$ & 94 & 28.9 \\
\hline \multirow{2}{*}{ Gender } & Male & 104 & 32 \\
& Female & 221 & 68 \\
\hline \multirow{2}{*}{ Race } & Malay & 155 & 47.7 \\
& Chinese & $\mathbf{1 0 8}$ & $\mathbf{3 3 . 2}$ \\
& Indian & 62 & 19.1 \\
\hline \multirow{2}{*}{ Geographic } & Urban & 209 & 64.3 \\
& Rural & 116 & 35.7 \\
\hline
\end{tabular}


We have designed four questions with 7 scales (from $1=$ strongly disagree to $7=$ strongly agree) to analyze and measure group influence. Here to analyze group influence, the first three questions are rounded as disagree; question four with no change meaning neutral and the last three questions have been rounded as agree.

As indicated in Table 2, most respondents with $51.6 \%$ agreed that friends significantly influence their behaviors to purchase something. Ask a relative for advice, media and ask colleagues/classmates for advice received $45.5 \%$, $45.3 \%$ and $42.8 \%$ ratings respectively.

Table 2. Group Influence Profile

\begin{tabular}{llll}
\hline Group Influence Items & Disagree & Percentage Neutral & Agree \\
\hline Friend influence on me to make purchase something & $37 \%$ & $11.4 \%$ & $51.6 \%$ \\
Ask a relative for advice & $42.8 \%$ & $11.7 \%$ & $45.5 \%$ \\
Ask colleague/classmates for advice & $41.5 \%$ & $15.7 \%$ & $42.8 \%$ \\
Media significantly influence me to make purchase decision & $34.7 \%$ & $20 \%$ & $45.3 \%$ \\
\hline
\end{tabular}

\subsection{Analysis}

According to Flynn and Pearcy (2001) and Grace (2005), used the Cronbach _ reliability coefficient, factor analysis and correlation analysis, the scale reliability and validity were evaluated. Nunnally and Bernstein (1994) recommend a minimum coefficient alpha result of 0.60 . Based on our findings, the reliability _ value for every factor is rated above 0.70 and consequently, all scales of every factor show internal consistency. In addition, the findings in Table 3, illustrate that age positively affect PI with $\mathrm{p}<0.05$. Besides, the effect of age group 17-21 (mean $=4.76)$ is more than age groups 22-26 (mean $=4.61)$ and 27-32 (mean $=4.56)$ on PI. H1 (a) is accepted. Moreover, gender positively affects purchase intention with $\mathrm{p}<0.05$. The effect of female (mean $=4.86$ ) is more significant than male (mean $=4.28$ ) on PI. H1 (b) is accepted. Last but not least, race positively influence on PI with $\mathrm{p}<0.05$. The Malays (mean $=4.76$ ) are more favorable to affect PI. H1 (c) is accepted.

H2: Geographic factor has positively influenced PI. The results illustrate that geographic factors have been positively influenced PI with $\mathrm{p}<0.05$. Besides, urban area with 5.11 is more favorable to influence PI. H2 is also accepted.

Table 3. Hypothesis Testing of PI (Demographic and Geographic)

\begin{tabular}{lccc}
\hline Independent Variables & Dependent Variable & Mean & Sig \\
\hline Demographic & PI & & 0.03 \\
Age & & 4.76 & \\
$17-21$ & & 4.61 & .000 \\
$22-26$ & & 4.56 & \\
$27-32$ & PI & & 0.01 \\
Gender & & 4.28 & \\
Male & PI & 4.86 & \\
Female & & & .000 \\
Race & & 4.76 & \\
Malay & & 4.44 & \\
Chinese & PI & 4.74 & \\
Indian & & 5.11 & \\
\hline Geographic & & 4.09 & \\
Urban & & & \\
Rural & & & \\
\hline
\end{tabular}

H3: Group positively influences PI;

Group positively influences PI with $\mathrm{p}<0.05$ (see Table 4). Findings showed that friends with greater mean (4.20) are more significantly to impact PI. The $\mathrm{p}<0.05$, so H3 is accepted. 
Table 4. Hypothesis Testing of PI (Group Influence)

\begin{tabular}{llll}
\hline Independent Variable & Dependent Variable & Mean & Sig \\
\hline Group Influence & PI & & .000 \\
Friend influence on me to make purchase something & & 4.20 & \\
Ask a relative for advice & & 3.95 \\
Ask colleague/classmates for advice & & 3.99 \\
Media significantly influence me to make purchase decision & & 4.11 \\
\hline
\end{tabular}

\subsection{Limitations}

In this research study, we have not measured the effect of culture on PI as a significant factor. Previous research demonstrated that consumers behave differently with different culture. Some of the items of PI might have higher dependability in some cultures and lower dependability in other cultures. As a result, future research could apply Malaysian culture to enhance the validity of the study thus gain better result.

Also, data analysis was limited to younger generation in Kuala Lumpur and Cyberjaya. Future research could incorporate data from customer groups from different regions and different age groups to obtain better results and increase the validity of research.

Since the results of this research study are based on demographic factors (age, gender and race), geographic and group influence, future research can investigate other factors such as income and situational factors. These would help marketers to better understand the customers' profile.

\section{Discussion on Findings}

The overall results show that there are varieties of behaviors among young Malaysian consumers. This is due to some reasons being that out of the 325 Malaysia consumers surveyed, we have obtained different results among different factors and variables.

Some of independent variables are more significantly to influence consumer PI as dependent variable. According to previous researches, younger consumers are more significant to influence on PI. It could be because younger consumers are more opened to experience and do less care about prices. Therefore, they will try to decide to make easier decision and intend to purchase something in return. This research study has also found out, when age of Malaysian customer increases, the effect of age on PI will be reduced. As a result, consumers with the age of 17-21 will more likely affect PI.

Gender positively affects PI and the female more significantly influences on PI. It can be because females are more affected by friends and classmates/colleagues (Safiek \& Hayatul, 2009). Furthermore, race positively affects PI as well. The effect of Malay is more than Chinese and Indian on PI. The Malays are often affected by friends and media. Also, this study and previous researches demonstrated that geographical factors have positively influenced PI. The effect of urban is more significant than rural on PI. This is due to some reasons such as urban consumers are more educated as well as the effect of Media on their decision making and PI is much more compared to rural consumers. Finally, group positively influences PI and the effect of friend on PI is more considerable than other group's items.

\section{Recommendations}

Based on our findings, there are some key points which can be applied by marketers and businessmen to gain better profit and even to perceive how to behave with consumers in the real world. One of the best recommendations identified is that marketers and businessmen should enhance their understandings and information on young consumers in Malaysia.

In the case of demographic, the youngest age group (17-21) is more significant in influencing PI. When the age of customer increases, the effect of age on PI is reduced. Moreover, female and Malays are more favorable to influence PI. Marketing managers should notice that the age group of 17-21, female and Malay respondents was more interested in this research study to influence PI. It shows that young female Malays could be one of the best target markets for marketing managers to concentrate in order to attract them and after that retain them for a long time.

In addition, urban consumers are more careful in their decision makings as well as purchase intention. Therefore, marketing managers should design and develop different types of products which can match both urban and rural consumers in Malaysia. 
Moreover, the effect of group on PI is different. The research reflects that the impact of friends (word of mouth) is more than other group's instruments. Therefore, marketing managers should be aware of power and the effect of word of mouth (WOM) on young Malaysian consumers. This means that influences of WOM on Malaysian consumer's PI is more than advertising and media. Consequently, marketing managers should know how to apply and make use of this group's instrument to absorb and maintain young Malaysian consumers for the long run.

\section{Conclusion}

This study has investigated the role of demographic factors (age, gender and race), geographic and group on PI amongst young generation in Malaysia. Questionnaires have distributed to young Malaysian consumers and 325 out of 350 respondents completely answered the questions, which was a valid and sufficient response rate. SPSS software has used to examine the influence of demographic, geographic and group on PI.

The result has showed that there is a positive connection among independent variables and dependent variable. Moreover, the outcomes of this research indicated that whenever age of the consumer increases, the effect of age group on PI will be reduced. Besides, being female, Malay, urban dwellers and friends (word of mouth) can influence PI more than other independent variables.

\section{Acknowledgement}

I would like to express my gratitude to Universiti Technologi Malaysia (UTM), which provided me the opportunity to do my $\mathrm{PhD}$ and broaden my academic and business horizons.

\section{References}

Abdul Razak, K., \& Kamarulzaman, K. (2009). Malay culture and consumer decision-making styles: an investigation on religious and ethnic dimensions. Jurnal Kemanusiaan Bil, 11, 14-28.

Ahasanul, H., Ali, K., \& Sabbir, R. (2006). Factors influencing buying behavior of piracy products and its impact to Malaysian market. International Review of Business Research Papers, 5(2), 383-401.

Cathy, B., \& Vincent, W. M. (2006). Male versus female consumer decision making styles. Journal of Business Research, 59, 1297-1300. http://dx.doi.org/10.1016/j.jbusres.2006.09.008

Chiao, C. C., \& Yang, C. C. (2010). The impact of recommendation sources on online purchase intentions: The moderating effects of gender and perceived risk. World Academy of Science, Engineering and Technology, 6, 111-114.

Flynn, L. R., \& Pearcy, D. (2001). Four subtle sins in scale development: some suggestions for strengthening the current paradigm. International Journal of Marketing Research, 43(4), 409-33.

Fon, S. O. J., Philip, K., \& Ata, T. J. (2008). Consumption patterns and silver marketing: an analysis of older consumers in Malaysia. Marketing Intelligence \& Planning, 26(7), 682-698. http://dx.doi.org/10.1108/02634500810916663

Grace, D. (2005). Consumer disposition toward satisfaction (CDS): scale development and validation. Journal of Marketing, 13(2), 20-31.

Heidi, M. N., Gerard, P. P., \& Alex, S. L. T. (2008). Linking sports sponsorship with purchase intentions: Team performance, stars, and the moderating role of social identification. European Journal of Marketing, 45(4), 551-566.

Keller, K. L. (2001). Building customer-based brand equity: creating brand resonance requires carefully sequenced brand-building efforts. Marketing Management, 10(2), 15-19.

Nabil, J., \& Imed, Z. (2010). The impact of label perception on the consumer's purchase intention: an application on food products. IBIMA Business Review, 2, 2-14.

Nunnally, J. C., \& Bernstein, I. H. (1994). Psychometre Theory. New York, NY: McGraw-Hill Publishing Company.

Rashidah, A. R., \& Fairuzana, H. M. A. (2006). Board, audit committee, culture and earnings management: $\begin{array}{llll}\text { Malaysian evidence. Managerial Auditing Journal, 21(7), 783-804. } & \text {. }\end{array}$ http://dx.doi.org/10.1108/02686900610680549

Safiek, M. (2009a). An investigation of consumer decision-making styles of young-adults in Malaysia. International Journal of Business and Management, 4(4), 140-148. 
Safiek, M. (2009b). Malaysian Chinese consumers: Their ethnic attitudes and shopping orientations. International Journal of Business and Management, 4(11), 53-62.

Safiek, M., \& Hayatul, S. S. (2009). Consumer decision-making styles in Malaysia: An exploratory study of gender differences. European Journal of Social Sciences, 10(4), 574-584.

Siti, N. B. A., \& Nurita, J. (2010). Organic food: A study on demographic characteristics and factors influencing purchase intentions among consumers in Klang Valley, Malaysia. International Journal of Business and Management, 5(2), 105-118.

Speed, R., \& Thompson, P. (2000). Determinants of Sports Sponsorship Response. Journal of the Academy of Marketing Science, 28(2), 26-238. http://dx.doi.org/10.1177/0092070300282004

Stephanie, W. (2003). The effect of music on perceived atmosphere and purchase intentions in a restaurant. Music and Psychology Research, 31, 93-112. http://dx.doi.org/10.1177/0305735603031001327

Syed, A. (2003). Digital divide and purchase intention: Why demographic psychology matters. Journal of Economic Psychology, 24(3), 321-327.

Wong, F. Y., \& Yahyah, S. (2008). Influence of brand loyalty on consumer sportswear. Journal of Economics and Management, 2, 221-236. 